the prosthetic substances. H. F. Richardson showed that death from intra-venous air embolism in dogs depends on the rate of injection; at very slow rates surprisingly large amounts of air can be injected before death ensues (through failure of the pulmonary circulation). B. C. Coles showed that the type of death in cases of criminal abortion, commonly ascribed to small amounts of air found in the heart at post-mortem, may be due rather to lethal amounts of toxic substances (such as potassium soaps) in the douche solution having entered the blood stream from the uterine cavity. According to D. Irwin, the tissue response to different samples of quartz is practically identical. W. R. Franks, L. D. Proctor and A. Duncan described a photo-electric dust estimator, designed to measure accurately and rapidly dust retainable by the lungs and therefore to estimate the dust hazard.

\title{
Recent Aeronautical Research
}

$\mathrm{T}$ HE report of the Aeronautical Research Committee, issued recently*, deals with a period of nearly two years, from April 1935 until December 1936. This is to cover a change of procedure, future reports being issued for the calendar year. The report opens with a well-merited tribute' to the memory of Sir Richard Glazebrook and Sir Joseph Petavel, who died during the period under review. They were both original members of the Advisory Committee for Aeronautics, appointed in 1909, and all who have had any connexion with aeronautics will appreciate how much the development of the science owes to them.

The outstanding feature of the period under review has been the increase in, and the still further demands for, high performance of aircraft. The major part of the Committee's activities are ob. viously directed towards this object. It is emphasized that the more recent equipment at the National Physical Laboratory and the Royal Aircraft Establishment, although elaborate and expensive, have made possible advances in the fundamentals of aircraft aerodynamical design to an extent that could never have been accomplished by the trialand-error methods of full-scale experimental flight alone. The compressed air tunnel and the one-foot high-speed tunnel at the former, and the $24-\mathrm{ft}$. wind tunnel at the latter, are cases in point.

The 24-ft. tunnel at the R.A.E. has been used principally for the investigation of engine-cooling problems. At high translational speeds, theory shows it should be possible to provide enough cooling without adding at all to the drag of the complete aeroplane, and this prediction has been supported by experimental results. As the induced drag at high speeds is very small, it follows that a welldesigned aircraft travelling at high speed need have a drag very little higher than that due to the friction between its exposed surfaces and the air.

Aeroplane speeds are now almost approaching the range in which compressibility becomes important, and the Committee, by undertaking research on compressibility effects, is taking steps to have information available by the time it is required. The apparatus used for this work is a one-foot high-speed tunnel, run from the exhaust of the compressed air tunnel. Tests on thick aerofoils have been done, and suggest that it may be necessary to take account of 'compressibility drag' when speeds of flight exceed four hundred miles per hour.

Much of the time of the compressed air tunnel has

* Aeronautical Research Committee. Report for the years 1935-36. Pp. $60+7$ plates. (London: H.M. Stationery Office.) 48 . net. been devoted to investigations of surface friction. At the Reynolds numbers of flight a surface roughness corresponding to excrescences of the order of onethousandth of an inch in height may be enough to increase the friction substantially. This measure of roughness is inappreciable at Reynolds numbers corresponding to those in ordinary atmospheric tunnels, so that although roughness may produce a difference in the behaviour of an actual aeroplane, the cause was not appreciated until this problem had been worked out.

Drag measurements have also been made in flight by means of a comb of small pitôt tubes which determine the difference in relative velocity between the air in the wake of the wing and the free air. It can also be applied in the compressed air tunnel, which will enable profile drag to be determined at Reynolds numbers of the order of those reached by fast modern aeroplanes.

Another problem has been to determine where on aeroplane wings the change from laminar to turbulent flow in the boundary layer takes place. As the drag associated with the turbulent boundary layer is considerably greater than that of the laminar layer, it is important to keep the transition point on the wing as far back as possible. It is suspected that protuberances in the surface of a wing near its leading edge may promote an early transition point and so increase the drag.

Modern high-speed machines have introduced other problems, particularly of stability. For example, directional stability is often unexpectedly good, although longitudinal stability is not so satisfactory. Further, increasing speed inevitably implies higher wing loading and thus introduces landing problems. The properties of flaps and other aids to stability, particularly when landing and taking off, have been studied, and work on gusts in the atmosphere is continuing.

Structural problems following upon the recent development of 'stressed skin' bodies and wings have shown that stabilizing members for flat, or slightly curved, sides of bodies need to be carefully studied for optimum efficiency. Tubular members are stronger for a given amount of material, but their use presents practical difficulties.

In aero-engine work, attention has been paid to the development of bi-fuel systems, which at the moment appear to be necessary with the use of 100 octane fuel. Direct fuel injection, supercharging, high boiling point liquids for cooling, spark ignition, and the compression ignition engine have been subjected to investigation in various details, but nothing revolutionary is proposed. 
The question of the size of sea-going aircraft has been studied in a general way, and the Committee expresses the opinion that no new scientific problem seems probable with flying boats of up to a hundred tons in weight.

The technical supplement to the report is sub- divided into sections dealing with : aerodynamics, fluid motion, stability and control, oscillation, spinning, structures, elasticity and fatigue, alloys, engines, aircraft noise, seaplanes, meteorology, accidents, administration including $(a)$ list of publications and (b) membership of sub-committees and panels.

\section{"Discovery" Investigations*}

$\mathrm{D}^{\mathrm{c}}$ URING the years 1935 and 1936 three volumes have been published containing reports on material collected by the "Discovery" expeditions, on many subjects by various workers. Vol. 11 is devoted entirely to plankton, and forms an introduction to the study of the plankton of the Antarctic, embodying as it does, a detailed discussion of methods and their value, besides extensive accounts of the distribution and migrations of plant and animal plankton, pre-eminently important for the understanding of the natural history of the Blue, Fin, Sei and Humpback whales. It is noteworthy that the first instance of vertical migration of phytoplankton is here shown in certain species of Coscinodiscus which ascend during the daytime, the reverse of the usual animal migration. It is constantly seen in the "Discovery" reports that Euphausia superba appears to be a key animal with regard to the distribution of Antarctic plankton, forming directly the food of the Blue and the Fin whales, and indirectly influencing the plankton in a variety of ways. A consideration of the relationship between the distribution of the whales and that of the plankton, and between the zooplankton and the phytoplankton, has led to the recognition of certain general principles of pelagicecology.

The remarkable patchiness in distribution of many of the plankton animals is emphasized, and Prof. Hardy's hypothesis of animal exclusion, showing that the more important plankton animals avoid the areas of dense phytoplankton, is dwelt upon at length. In this connexion, the phosphate values are shown to be of extreme importance, and relative reduction in phosphate content appears to be a better index in studying the zoo-phytoplankton relationship than the phytoplankton itself, giving a measurement of phytoplankton over a little time in the past. The appearance of exclusion from regions of low phosphate (high phytoplankton) applies to animals belonging to widely different groups, and it is considered that if the distribution of the animals is being modified by the phytoplankton, this modification must be brought

* Discovery Reports. Issued by the Discovery Committee, Colonial Office, London, on behalf of the Government of the Dependencies of the Falkland Islands. Vol 11. The Plankton of the South Georgia Whaling Grounds and Adjacent Waters, 1926-1927. Continuous Plankton Recorder. By A. C. Hardy. Pp. 457-510+4 plates. 9s. net. Observations on the Uneven Distribution of Oceanic Plankton. By A. C. Hardy. Pp. 511-538. 4s. net. Vol. 12. Coast Fishes, Part 1 : The South Atlantic. By J. R. Norman. Pp. 58. 58. net. Polychaete Worms, II. By C. C. A. Monro. Pp. 59-198. 188. net Echinoidea and Ophiuroidea. By Th. Mortensen. Pp. 199-348+9 plates. 278. 6d. net. The Birds of the South Orkney Islands. By R. A. B. Ardley. Pp. 349-376 + plates 10-12. 68. net. Larvæ of Decapod Crustacea. By Dr. Robert Gurney. Pp. 377-440. 9s. net. Vol. 13. Foraminifera. Part 4: Additional Records from the Weddell Sea Sector from Material obtained by the S.Y. Scotia. By Arthur Earland. Pn. $76+3$ plates. 128. net. The Royal Research Ship Discovery II. By R. A. B. Ardley and Dr. N. A. Mackintosh. Pp. 77-106+plates 3-13. 98. net. A Report on Oceanographical Investigations in the Peru Coastal Current. By E. R. Gunther. Pp. 107-276 + plates 14-16. 268. net. Rhincalanus gigas (Brady), a Copepod of the Southern Macroplankton. By Dr. F. D. Ommanney. Pp. 277-384. 158. net. (Cambridge: At the Universitv Press, 1935-1936.) about by variations in the vertical migration in conjunction with differing water movements at different levels. All the animals which show the exclusion effects have marked vertical migrations. This first report is intended to form an introduction to pelagic ecology of the Antarctic seas. The plankton com. munity is considered in relation to its hydrological background, and to the distribution of the Blue and Fin whales which feed upon the pilankton and form the object of such an important fishery in these seas.

The second plankton report deals with the con. tinuous plankton recorder invented by Prof. Hardy. This has now been much improved, and a full account is given of its construction, method of working and the advantages and limitations of the results obtained in its use. The third paper deals with observations on the uneven distribution of oceanic plankton, and describes records of plankton taken in the open ocean during the voyages of the R.R.S. Discovery and R.R.S. William Scoresby in the years 1925-27 with the original form of continuous plankton recorder. They were made with the view of studying the main fluctuations in the planktonic density along uninterrupted lines of observation. These lines varied from 23 miles to more than 100 miles in length, and were made in different oceanic regions from the tropical to the antarctic zone. The records demonstrate marked fluctuations in the distribution of the main planktonic groups of animals, no less marked in the tropics than in the antarctic zone. The existence of a rhythm in the distributional fluctuations is tentatively suggested, a rhythm which varies on different occasions.

Vol. 12 embodies a variety of subjects, the first being the coast fishes from the South Atlantic by J. R. Norman. The term 'coast fishes' includes not only the littoral forms, but also fishes that may occur at no great distanee from the coasts in water down to two or three hundred fathoms deep, and that are not pelagic or bathypelagic. C. C. A. Monro con. tinues his description of the polychaete worms (2), Dr. Th. Mortensen reports on the Echinoidea and Ophiuroidea, R. A. B. Ardley on the birds of the South Orkney Islands and Dr. R. Gurney begins his study of the decapod larvæ (Stenopidea, Amphionidø and Phyllosoma).

In Vol. 13 A. Earland continues the Foram. inifera (4), R. A. B. Ardley describes the R.R.S. Discovery $I I$, its construction and design, accommodation for research, scientific equipment and laboratory methods, E. R. Gunther writes on oceanographical investigations in the Peru coastal current, and Dr. F. D. Ommaney contributes an extensive paper on the copepod Rhincalanus gigas (Brady) which is very important in Antarctic waters and is reported on fully in every aspect as a representative plankton animal in these regions. 